\title{
Versatility of Retzius-Sparing Prostatectomy: Its Application in Renal Transplant Patient and En-bloc Abdominal-Perineal Resection
}

\author{
Chi Hang Yee, MBBS, FRCS, MD ${ }^{1}$, Sze Jin Adrian Yu, MBChB ${ }^{1}$, Man-Fung Ho, MBChB, FRCS ${ }^{2}$, \\ Kaori Futaba, MBChB, FRCS ${ }^{2}$ (1) , Tony Mak, MBChB, FRCS ${ }^{2}$, Jeremy Yuen Chun Teoh, MBBS, FRCS ${ }^{1}$, \\ Peter Ka Fung Chiu, MBChB, FRCS, PhD ${ }^{1}$, Simon Siu-Man Ng, MBChB, MD, FRCS ${ }^{2}$, and \\ Chi-Fai Ng, MBChB, FRCS, MD ${ }^{1}$
}

${ }^{1}$ S.H. Ho Urology Centre, Department of Surgery, Prince of Wales Hospital, The Chinese University of Hong Kong, Shatin, Hong Kong; ${ }^{2}$ Division of Colorectal Surgery, Department of Surgery, Prince of Wales Hospital, The Chinese University of Hong Kong, Shatin, Hong Kong

The Retizius-sparing (RS) approach to prostatectomy has several proposed advantages over the conventional retropubic approach. This includes reduced post-prostatectomy stress urinary incontinence rates and better preservation of potency. ${ }^{1-3}$ While a smaller workspace may render this technique more technically challenging, this approach provides an advantage beyond functional outcome in certain clinical situations. We present two scenarios where Retzius-sparing robotic-assisted radical prostatectomy (RS-RARP) provided additional versatility that was translated into a more desired clinical outcome.

The first case was a 76-year-old renal transplant patient diagnosed with intermediate-risk prostate cancer. His wellfunctioning low-lying graft kidney in the left lower quadrant was in close relation to the prostate gland, precluding either conventional retropubic prostatectomy or radiotherapy as a treatment option. RS-RARP was performed for the patient, yielding satisfactory oncological and functional outcomes. The second case was a 61-year-old patient who had a rectal tumour with suspected prostate invasion on MRI. After neoadjuvant chemotherapy and radiotherapy, robotic en-bloc abdominal-perineal resection of the rectum,

(c) The Author(s) 2021

First Received: 18 May 2021

Accepted: 31 August 2021;

Published Online: 26 September 2021

C. H. Yee, MBBS, FRCS, MD

e-mail: yeechihang@surgery.cuhk.edu.hk using a Retzius-sparing prostatectomy technique, was performed to save the patient from total exenteration and double stomata. A modified RS-RARP was adopted to keep the surgical plane between the rectum and prostate. Both procedures were uneventful.

In conclusion, the Retzius-sparing approach is a versatile technique which helps the surgeon to conduct a prostatectomy when special anatomical considerations are at play.

DISCLOSURE All authors have no conflict of interest to declare.

Supplementary Information The online version contains supplementary material available at https://doi.org/10.1245/s10434021-10804-6.

OPEN ACCESS This article is licensed under a Creative Commons Attribution 4.0 International License, which permits use, sharing, adaptation, distribution and reproduction in any medium or format, as long as you give appropriate credit to the original author(s) and the source, provide a link to the Creative Commons licence, and indicate if changes were made. The images or other third party material in this article are included in the article's Creative Commons licence, unless indicated otherwise in a credit line to the material. If material is not included in the article's Creative Commons licence and your intended use is not permitted by statutory regulation or exceeds the permitted use, you will need to obtain permission directly from the copyright holder. To view a copy of this licence, visit http://creativecommons. org/licenses/by/4.0/.

\section{REFERENCES}

1. Dalela D, Jeong W, Prasad MA, et al. A pragmatic randomized controlled trial examining the impact of the Retzius-sparing 
approach on early urinary continence recovery after robot-assisted radical prostatectomy. Eur Urol. 2017;72(5):677-85. https://doi. org/10.1016/j.eururo.2017.04.029.

2. Galfano A, Di Trapani D, Sozzi F, et al. Beyond the learning curve of the Retzius-sparing approach for robot-assisted laparoscopic radical prostatectomy: Oncologic and functional results of the first 200 patients with $\geq 1$ year of follow-up. Eur Urol. 2013;64(6):974-80. https://doi.org/10.1016/j.eururo.2013.06.046.
3. Lim SK, Kim KH, Shin TY, et al. Retzius-sparing robot-assisted laparoscopic radical prostatectomy: Combining the best of retropubic and perineal approaches. BJU Int. 2014;114(2):236-44. h ttps://doi.org/10.1111/bju.12705.

Publisher's Note Springer Nature remains neutral with regard to jurisdictional claims in published maps and institutional affiliations. 